Case Reports in
Gastroenterology
Case Rep Gastroenterol 2021;15:344-351

DOI: 10.1159/000513803

Published online: March 11, 2021 (c) 2021 The Author(s)

Published by S. Karger AG, Basel www.karger.com/crg

This article is licensed under the Creative Commons Attribution-NonCommercial 4.0 International License (CC BY-NC) (http://www.karger.com/Services/OpenAccessLicense). Usage and distribution for commercial purposes requires written permission.

\title{
Hepatic Epithelioid Hemangioendothelioma Presenting Synchronously with Hepatocellular Carcinoma
}

\author{
Hiroki Kanno Toshihiro Sato Ryuta Midorikawa Satoki Kojima \\ Shogo Fukutomi Yuichi Goto Yoriko Nomura Munehiro Yoshitomi \\ Ryuichi Kawahara Hisamune Sakai Toru Hisaka Yoshito Akagi \\ Koji Okuda
}

Department of Surgery, Kurume University School of Medicine, Kurume, Japan

\section{Keywords}

Epithelioid hemangioendothelioma $\cdot$ Hepatocellular carcinoma $\cdot$ Liver

\begin{abstract}
Hepatic epithelioid hemangioendothelioma (EHE) is a rare malignant tumor with unknown pathogenesis. Herein, we report a case of a hepatic EHE presenting synchronously with a hepatocellular carcinoma (HCC). To the best of our knowledge, this is the second case report of synchronous hepatic EHE and HCC. An 84-year-old man presented with back pain. During examination, a tumor in liver segment 3 was coincidentally detected. Tumor marker (carbohydrate antigen 19-9, alpha-fetoprotein, and protein induced by vitamin $\mathrm{K}$ absence or antagonist-II) levels were elevated. Contrast-enhanced computed tomography revealed perinodular enhancement in the arterial and portal phases. Another tumor was detected in liver segment 2, which was homogeneously enhanced in the arterial phase, followed by washout in the portal and late phases. Based on these imaging findings, we diagnosed the tumor in segment 3 as a solitary cholangiocellular carcinoma and the tumor in segment 2 as a solitary HCC. Lateral sectionectomy of the liver was performed. Microscopically, spindle-shaped and epithelioid cells were present in the tumor in segment 3. On immunohistochemistry, the tumor cells were positive for CD31 and CD34, focally positive for D2-40, and negative for AE1/AE3. Therefore,
\end{abstract}

\begin{tabular}{ll}
\hline & Hiroki Kanno \\
Department of Surgery & Kurume University School of Medicine \\
& 67 Asahi-machi, Kurume 830-0011 (Japan) \\
kanno_hiroki@med.kurume-u.ac.jp
\end{tabular}




\section{Case Reports in Gastroenterology}

Case Rep Gastroenterol 2021;15:344-351

\begin{tabular}{l|l}
\hline DOI: 10.1159/000513803 & $\odot 2021$ The Author(s). Published by S. Karger AG, Basel
\end{tabular} www.karger.com/crg

Kanno et al.: Hepatic Epithelioid Hemangioendothelioma Presenting Synchronously with Hepatocellular Carcinoma

the tumor in segment 3 was ultimately diagnosed as an EHE and the tumor in segment 2 as a well-differentiated HCC. Preoperative diagnosis of EHE is difficult owing to the lack of specific findings. Intratumoral calcification, halo sign, and lollipop sign are occasionally found in EHE and are useful imaging findings for diagnosis. Clinical behavior is unpredictable, ranging from indolent growth to rapid progression. Clinical or pathological predictors of the course of EHE are urgently required.

\section{Introduction}

Epithelioid hemangioendothelioma (EHE) is a low- to intermediate-grade malignancy with an incidence of $<0.01$ per 10,000 people [1]. Owing to its rarity, its etiology and pathogenesis are still unknown. Sites of EHE include the lungs, soft tissue, visceral organs, bone, and liver. Since it lacks specific imaging and pathological features, EHE is difficult to diagnose preoperatively. Common misdiagnoses of EHE include cholangiocellular carcinoma (CCC), sclerosing hepatocellular carcinoma (HCC), metastatic carcinoma, and angiosarcoma. The clinical behavior of EHE is unpredictable, ranging from indolent growth to rapid progression. However, there are no biomarkers for aggressive behavior or established treatment guidelines. We here report a case that was misdiagnosed as synchronous solitary CCC and solitary HCC based on preoperative imaging findings and elevated tumor marker levels, but was postoperatively confirmed as EHE based on pathology. To the best of our knowledge, this is the second case report of synchronous hepatic EHE and HCC.

\section{Case Presentation}

An 84-year-old man presented with back pain. During examination for the cause of the pain, a liver tumor was coincidentally detected on computed tomography (CT). His medical history included cholangiolocellular carcinoma, which had been treated via anterior sectionectomy of the liver 11 years previously. He had not excessively consumed alcohol in the past and had no underlying liver disease due to viral hepatitis or alcoholic or nonalcoholic steatohepatitis. Tumor recurrence had not been confirmed after the operation.

On laboratory tests, almost all variables were within normal limits. The Child-Pugh score was 5 points and the platelet count was $12.6 \times 10^{4} / \mu \mathrm{L}$. Both hepatitis B surface antigen and anti-hepatitis $\mathrm{C}$ antibody were negative. Tumor marker levels were elevated as follows: carcinoembryonic antigen: $8.2 \mathrm{ng} / \mathrm{mL}$; carbohydrate antigen 19-9: $69.2 \mathrm{U} / \mathrm{mL}$; alpha-fetoprotein: $43.3 \mathrm{ng} / \mathrm{mL}$; and protein induced by vitamin $\mathrm{K}$ absence or antagonist-II: $820 \mathrm{nAU} / \mathrm{mL}$.

Ultrasound detected a hypoechoic irregular heterogeneous tumor, $38 \mathrm{~mm}$ in diameter, in liver segment 3 . The liver capsule adjacent to the tumor was retracted, and the intrahepatic bile duct in the tumor periphery was dilated. Penetration of the tumor center by the hepatic artery was also observed. CT confirmed the presence of a low-density irregular nodule in liver segment 3, and the nodule showed perinodular contrast medium-based enhancement in the arterial and portal phases (Fig. 1a-c). The tumor in liver segment 3 had heterogeneous low signal intensity on T1-weighted magnetic resonance imaging (MRI), high signal intensity on T2-weighted MRI, and peripheral high signal intensity on diffusion-weighted MRI. On Gd-EOBDTPA-enhanced MRI, it was enhanced perinodularly in the arterial and portal phases, and its

\section{Karger'=}




\section{Case Reports in Gastroenterology}

Case Rep Gastroenterol 2021;15:344-351 DOI: $10.1159 / 000513803$

(c) 2021 The Author(s). Published by S. Karger AG, Basel www.karger.com/crg

Kanno et al.: Hepatic Epithelioid Hemangioendothelioma Presenting Synchronously with Hepatocellular Carcinoma

center was faintly enhanced in the hepatobiliary phase (Fig. 2). Positron emission tomography/CT revealed high accumulation in the tumor, with a maximum standardized uptake volume of 5.5. Contrast-enhanced CT also detected a tumor in liver segment 2, with homogeneous enhancement in the arterial phase, followed by washout in the portal and late phases (Fig. 1df). There was no accumulation in this tumor on positron emission tomography/CT.

Based on the imaging findings and elevated tumor marker levels, we diagnosed the tumor in liver segment 2 as a solitary HCC and the tumor in liver segment 3 as a solitary CCC or a combined HCC and cholangiocarcinoma. After diagnosis, we performed lateral sectionectomy of the liver. The macroscopic findings of the surgical specimens were an irregular whitish tumor with capsular retraction in liver segment 3 and a round yellowish tumor in liver segment 2. Microscopically, spindle-shaped cells, cells with intracytoplasmic vacuoles, and eosinophilic epithelioid cells were present in the tumor in liver segment 3 and were accompanied by mucoid and fibrous stroma. The tumor cells spread into the sinusoid at the tumor edge. On immunohistochemistry, the tumor cells with intracytoplasmic vacuoles in liver segment 3 were positive for CD31 and CD34, focally positive for D2-40, and negative for AE1/AE3 (Fig. 3). Therefore, the tumor in liver segment 3 was diagnosed as an EHE and the tumor in liver segment 2 as a well-differentiated HCC.

The postoperative course was uneventful. The patient was discharged on postoperative day 14. Four months after the operation, multiple bilateral lung nodules appeared. Transbronchial lung biopsy was performed, and the tumor was diagnosed as an EHE histologically. Since the patient declined further treatment for metastasis, he has been followed up since without any treatment. He remains alive 15 months after the liver operation.

\section{Discussion}

Since hepatic EHE was first described in 1982 as a soft tissue vascular cancer with a clinical course between that of hemangioma and angiosarcoma [2], more than 400 cases have been reported [3]. EHE appears more often in women than in men, with a female:male ratio of $3: 2$. The median age at diagnosis is 41.7 years, ranging from 3 to 86 years, and $87 \%$ of patients have multifocal lesions, with solitary nodules occurring in only $13 \%$. The clinical behavior of EHE is unpredictable, ranging from indolent growth to rapid progression. Treatment options for EHE are liver resection, liver transplantation, transcatheter arterial chemoembolization, radioablation, and chemotherapy, but there are no established treatment guidelines. In the present case, we performed liver resection for synchronous solitary HCC and EHE. To the best of our knowledge, this is only the second case report of synchronous HCC and EHE [4]. No report to date has uncovered a common background liver disease for EHE and HCC.

Preoperative diagnosis of EHE via imaging is difficult because EHE lacks specific features. EHE usually presents as hypoechoic irregular nodules on ultrasound. Most lesions appear to have a low density on plain CT, with perinodular enhancement to heterogeneous hyperenhancement on contrast-enhanced CT. EHE has a low signal intensity on T1-weighted MRI, intermediate to high signal intensity on T2-weighted MRI, and high signal intensity on diffusionweighted MRI. Some reports state that intratumoral calcification, capsular retraction, halo sign, and lollipop sign are useful imaging findings for distinguishing EHE on CT or MRI [5-7]. However, intratumoral calcification occurs in only $12.7 \%$ of EHEs [3]. Capsular retraction results from fibroproliferative reactions of the tumor and consequent invagination of the adjacent liver capsule, but is not unique to EHE as it sometimes occurs in metastatic carcinoma or

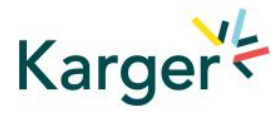




\section{Case Reports in Gastroenterology}

Case Rep Gastroenterol 2021;15:344-351

DOI: 10.1159/000513803

(c) 2021 The Author(s). Published by S. Karger AG, Basel www.karger.com/crg

Kanno et al.: Hepatic Epithelioid Hemangioendothelioma Presenting Synchronously with Hepatocellular Carcinoma

CCC. The halo sign - a low-intensity thin ring surrounding a high-intensity core with a slightly more intense peripheral halo - is found in $10.4-37.5 \%$ of EHE cases [3, 8]. The lollipop sign is specific to EHE. It signifies the infiltration of tumor cells into the hepatic vessels and sinusoids and the consequent tapering or disruption of the portal vein or a hepatic artery at the tumor edge [6]. The presence of a central enhancing scar and irregular strong enhancement of the lesions do not fulfill the criteria of the lollipop sign, and the vein should terminate smoothly at the edge or immediately inside the rim of the lesion. Although the lollipop sign is the most useful imaging feature of EHE, it is found in only $13 \%$ of cases [9]. In the present case, a hepatic artery penetrated the tumor center, but vascular termination at the tumor edge was not confirmed; thus, presence of a lollipop sign was not established. Moreover, our case had findings similar to those seen in CCC, such as retraction sign and bile duct dilatation, and tumor marker levels were elevated. The presence of the synchronous HCC also added to the confusion. Thus, it was quite difficult to diagnose this case correctly.

Histological diagnosis of EHE is also challenging. EHE can be misdiagnosed as other cancers, such as CCC, sclerosing HCC, metastatic carcinoma, and angiosarcoma. Immunohistochemistry is a powerful tool for differentiating these tumor types. The mesenchymal markers CD31, CD34, and factor VIII test positive in EHE and are, therefore, useful for distinguishing EHEs from epithelial tumors, such as CCCs, HCCs, and some types of metastatic carcinoma. However, hemangiomas and angiosarcomas also express CD31, CD34, and factor VIII. D2-40, also known as podoplanin, is widely used for identifying lymphatic vessels. In the study by Fujii et al. [10], D2-40 was expressed in 78\% of EHE cases but not in other hepatic tumors, such as hemangiomas, angiosarcomas, angiomyolipomas, HCCs, CCCs, or metastatic tumors. Some reports suggest that calmodulin-binding transcription activator 1 (CAMTA1) is the most specific EHE marker: CAMTA1 is overexpressed in approximately $90 \%$ of EHE cases but only in $4 \%$ of angiosarcoma cases [11]. However, CAMTA1 has not been widely used to date. Therefore, immunohistochemistry using CD31, CD34, factor VIII, and D2-40 is needed to diagnose EHE.

There is no standard treatment for EHE. In many cases, a surgical approach is selected. Liver resection is performed in resectable cases with singular tumors or unilobar tumors. About $87 \%$ of EHE cases present as multinodular tumors, with metastases in $36.6 \%$ at the time of diagnosis [3]. Such cases usually require liver transplantation. Some researchers suggest that metastases at the time of diagnosis may not contraindicate surgery because metastatic sites do not significantly affect overall survival $(O S)[12,13]$. In a review of 30 EHE patients, liver resection and liver transplantation had better disease-free survival and OS rates than chemotherapy or no treatment [12]: the 1-, 3-, and 5-year disease-free survival rates were 78,62 , and $62 \%$ for liver resection and 64,46 , and $46 \%$ for liver transplantation, respectively, and the 1-, 3-, and 5-year OS rates were 100, 86, and 86\% for liver resection and 91, 73, and $73 \%$ for liver transplantation, respectively. On the other hand, the 1-, 3-, and 5-year OS rates in the absence of surgery were 57,43 , and $29 \%$, respectively. Thomas et al. [14] reported similar 5-year OS rates for EHE patients who underwent surgery, chemotherapy, embolization, or observation. Additionally, observation without treatment shows favorable outcomes in pediatric EHE cases [15]. However, definitive biomarkers of EHE aggressiveness have not been established. Clinical or pathological predictors are urgently needed to improve outcomes.

In conclusion, EHE is a rare malignant tumor with a challenging preoperative diagnosis, as also illustrated in this case. Since its clinical behavior is unpredictable, definitive

\section{Karger'"}




\section{Case Reports in Gastroenterology}

\begin{tabular}{l|l}
\hline Case Rep Gastroenterol 2021;15:344-351 \\
\hline DOI: 10.1159/000513803 & $\begin{array}{l}\text { ○ 2021 The Author(s). Published by S. Karger AG, Basel } \\
\text { www.karger.com/crg }\end{array}$ \\
\hline
\end{tabular}

Kanno et al.: Hepatic Epithelioid Hemangioendothelioma Presenting Synchronously with Hepatocellular Carcinoma

biomarkers for both preoperative diagnosis and tumor aggressiveness are needed to facilitate appropriate treatment.

\section{Acknowledgments}

The authors would like to thank Editage (www.editage.com) for English language editing.

\section{Statement of Ethics}

Ethical approval was obtained from the Ethics Committee of Kurume University. Written informed consent was obtained from the patient for publication of this case report and accompanying images.

\section{Conflict of Interest Statement}

The authors declare that they have no competing interests.

\section{Funding Sources}

The authors declare that this work was not supported by any grants or funding.

\section{Author Contributions}

H. Kanno drafted the manuscript. Y. Akagi and K. Okuda supervised the study. T. Sato, R. Midorikawa, S. Kojima, S. Fukutomi, Y. Goto, Y. Nomura, M. Yoshitomi, R. Kawahara, H. Sakai, and $\mathrm{T}$. Hisaka performed the perioperative management of the patient.

\section{References}

1 Hertl M, Cosimi AB. Liver transplantation for malignancy. Oncologist. 2005 Apr;10(4):269-81.

2 Weiss SW, Enzinger FM. Epithelioid hemangioendothelioma: a vascular tumor often mistaken for a carcinoma. Cancer. 1982 Sep;50(5):970-81.

3 Mehrabi A, Kashfi A, Fonouni H, Schemmer P, Schmied BM, Hallscheidt P, et al. Primary malignant hepatic epithelioid hemangioendothelioma: a comprehensive review of the literature with emphasis on the surgical therapy. Cancer. 2006 Nov;107(9):2108-21.

4 Athanasopoulos PG, Hadjittofi C, Luong TV, O’Beirne J, Sharma D. Synchronous Hepatic Epithelioid Hemangioendothelioma and Hepatocellular Carcinoma: First Case Report in the Literature and Challenges. Medicine (Baltimore). 2015 Aug;94(34):e1377.

5 Yang DM, Kim HS, Cho SW, Kim HS. Pictorial review: various causes of hepatic capsular retraction: CT and MR findings. Br J Radiol. 2002 Dec;75(900):994-1002.

6 Alomari AI. The lollipop sign: a new cross-sectional sign of hepatic epithelioid hemangioendothelioma. Eur J Radiol. 2006 Sep;59(3):460-4.

7 Miller WJ, Dodd GD 3rd, Federle MP, Baron RL. Epithelioid hemangioendothelioma of the liver: imaging findings with pathologic correlation. AJR Am J Roentgenol. 1992 Jul;159(1):53-7. 


\section{Case Reports in Gastroenterology}

\begin{tabular}{l|l}
\hline Case Rep Gastroenterol 2021;15:344-351 \\
\hline DOI: 10.1159/000513803 & $\begin{array}{l}\text { @ 2021 The Author(s). Published by S. Karger AG, Basel } \\
\text { www.karger.com/crg }\end{array}$ \\
\hline
\end{tabular}

Kanno et al.: Hepatic Epithelioid Hemangioendothelioma Presenting Synchronously with Hepatocellular Carcinoma

8 Zhao XY, Rakhda MI, Habib S, Bihi A, Muhammad A, Wang TL, et al. Hepatic epithelioid hemangioendothelioma: A comparison of Western and Chinese methods with respect to diagnosis, treatment and outcome. Oncol Lett. 2014 Apr;7(4):977-83.

9 Zhou Y, Hou P, Wang F, Li B, Gao J. Primary hepatic malignant vascular tumors: a follow-up study of imaging characteristics and clinicopathological features. Cancer Imaging. 2020 Aug;20(1):59.

10 Fujii T, Zen Y, Sato Y, Sasaki M, Enomae M, Minato H, et al. Podoplanin is a useful diagnostic marker for epithelioid hemangioendothelioma of the liver. Mod Pathol. 2008 Feb;21(2):125-30.

11 Doyle LA, Fletcher CD, Hornick JL. Nuclear Expression of CAMTA1 Distinguishes Epithelioid Hemangioendothelioma From Histologic Mimics. Am J Surg Pathol. 2016 Jan;40(1):94-102.

12 Grotz TE, Nagorney D, Donohue J, Que F, Kendrick M, Farnell M, et al. Hepatic epithelioid haemangioendothelioma: is transplantation the only treatment option? HPB (Oxford). 2010 0ct;12(8):54653.

13 Lerut JP, Orlando G, Adam R, Schiavo M, Klempnauer J, Mirza D, et al.; European Liver Transplant Registry. The place of liver transplantation in the treatment of hepatic epitheloid hemangioendothelioma: report of the European Liver Transplant Registry. Ann Surg. 2007 Dec;246(6):949-57; discussion 957.

14 Thomas RM, Aloia TA, Truty MJ, Tseng WH, Choi EA, Curley SA, et al. Treatment sequencing strategy for hepatic epithelioid haemangioendothelioma. HPB (Oxford). 2014 Jul;16(7):677-85.

15 Emad A, Fadel S, El Wakeel M, Nagy N, Zamzam M, Kieran MW, et al. Outcome of Children Treated for Infantile Hepatic Hemangioendothelioma. J Pediatr Hematol Oncol. 2020 Mar;42(2):126-30.
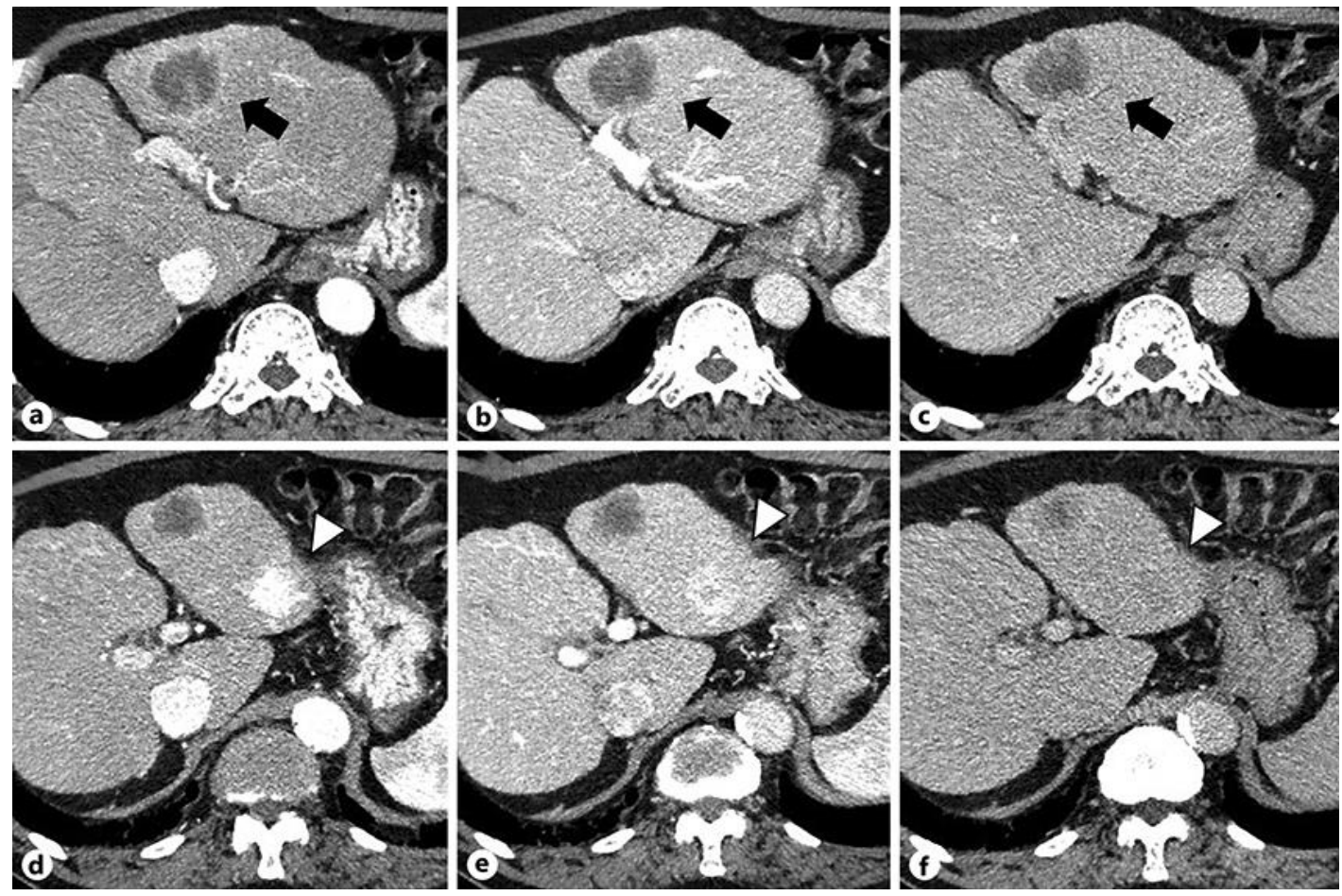

Fig. 1. On contrast-enhanced computed tomography, the tumor in liver segment 3 showed perinodular enhancement in the arterial and portal phases (black arrows). The tumor in liver segment 2 was homogeneously enhanced in the arterial phase, followed by washing out in the portal and late phases (white arrowheads). a, d Arterial phase. b, e Portal phase. c, f Late phase.

\section{Karger'}




\section{Case Reports in Gastroenterology}

\begin{tabular}{l|l}
\hline Case Rep Gastroenterol 2021;15:344-351 \\
\hline DOI: 10.1159/000513803 & $\begin{array}{l}\text { @ 2021 The Author(s). Published by S. Karger AG, Basel } \\
\text { www.karger.com/crg }\end{array}$ \\
\hline
\end{tabular}

Kanno et al.: Hepatic Epithelioid Hemangioendothelioma Presenting Synchronously with Hepatocellular Carcinoma
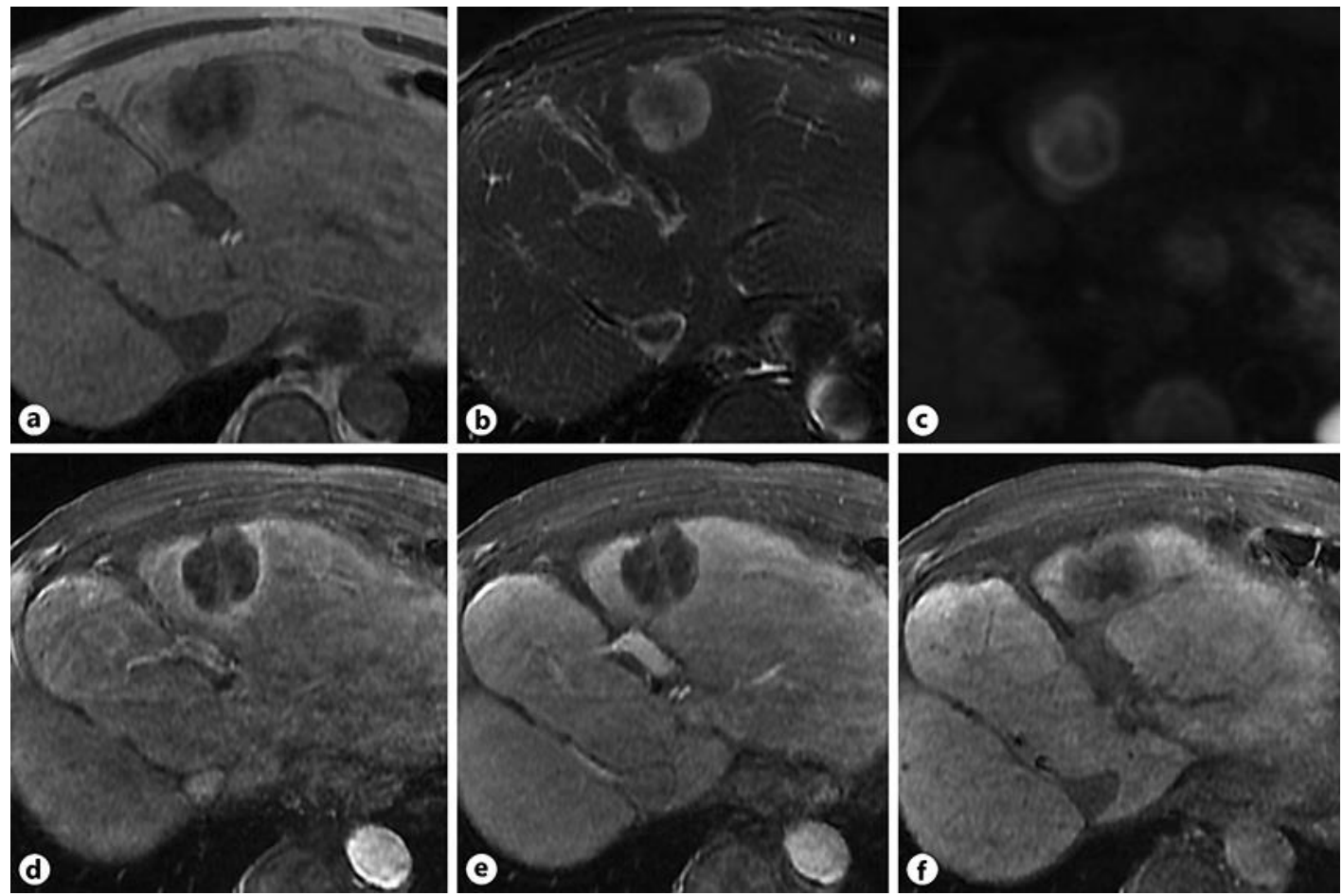

Fig. 2. The tumor in liver segment 3 showed heterogeneous low signal intensity on T1-weighted MRI (a), high signal intensity on T2-weighted MRI (b), and peripheral high signal intensity on diffusion-weighted MRI (c). On Gd-EOB-DTPA-enhanced MRI, the tumor in liver segment 3 was enhanced perinodularly in the arterial (d) and portal (e) phases, and the tumor center was faintly enhanced in the hepatobiliary phase (f). MRI, magnetic resonance imaging.

\section{Karger'}


Case Reports in Gastroenterology

\begin{tabular}{l|l}
\hline Case Rep Gastroenterol 2021;15:344-351 \\
\hline DOI: 10.1159/000513803 & $\begin{array}{l}\text { @ 2021 The Author(s). Published by S. Karger AG, Basel } \\
\text { www.karger.com/crg }\end{array}$ \\
\hline
\end{tabular}

Kanno et al.: Hepatic Epithelioid Hemangioendothelioma Presenting Synchronously with Hepatocellular Carcinoma
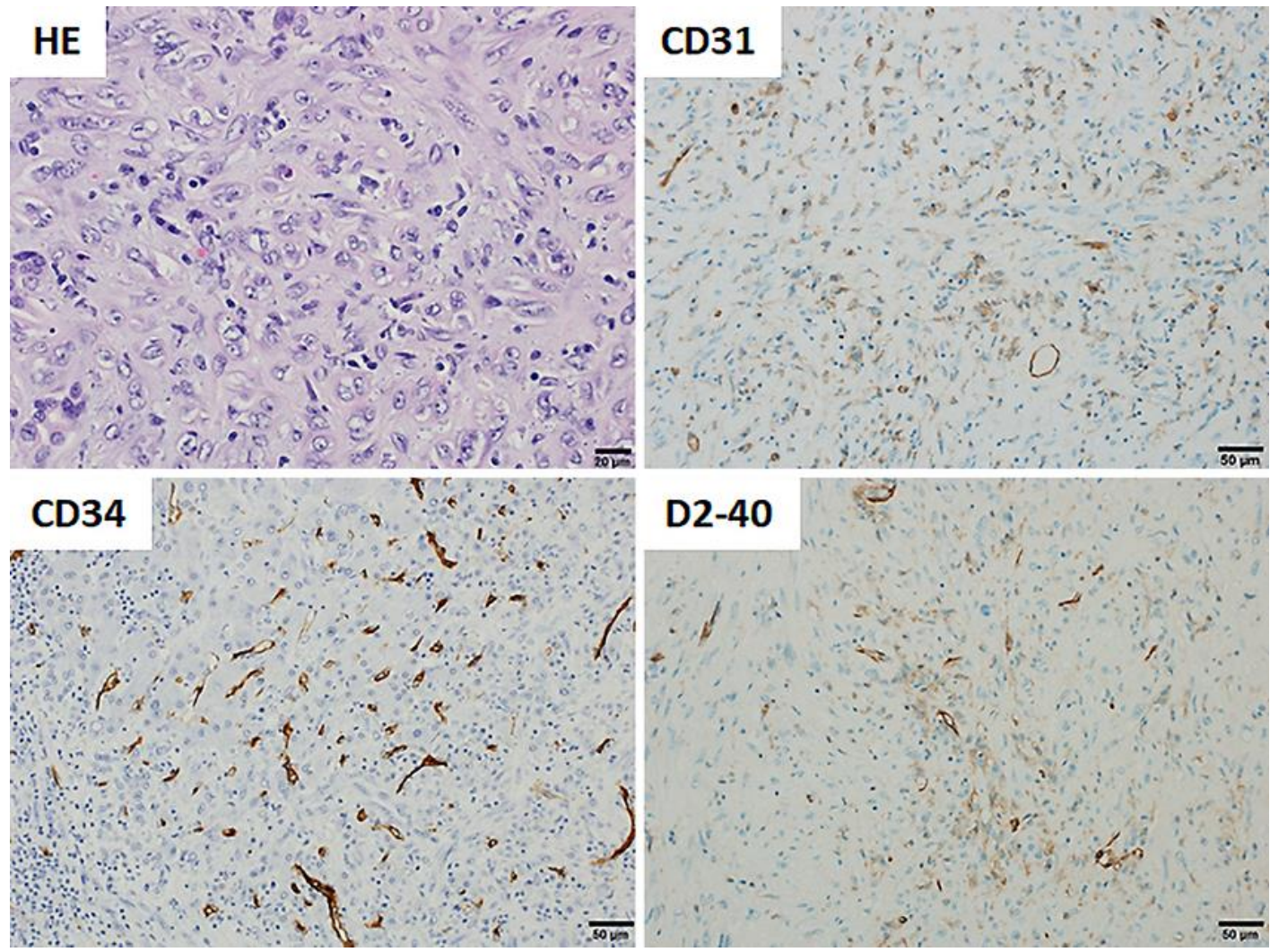

Fig. 3. Spindle-shaped cells, cells with intracytoplasmic vacuoles, and eosinophilic epithelioid cells were present in the tumor in liver segment 3 and were accompanied by mucoid and fibrous stroma. On immunohistochemistry, the tumor cells with intracytoplasmic vacuoles were positive for CD31 and CD34 and focally positive for D2-40. 